\title{
Jurisdicción especial indígena, derecho colombiano y normativa internacional: la necesidad de un equilibrio en el marco de la extracción de minerales y el impacto de género*
}

Special Indigenous Jurisdiction, Colombian Law and International

Regulations: Need for a Balance in the Framework of Extractive Industry and Gender Impact

Jurisdição especial indígena, direito colombiano e normativa internacional: a necessidade de um equilíbrio no marco da extração de minerais e o impacto de gênero

\author{
JORDI FEO VALERO
}

FECHA DE RECEPCIÓN: 21 DE DICIEMBRE DE 2018. FECHA DE APROBACIÓN: 10 DE ABRIL DE 2019

Doi: http://dx.doi.org/10.12804/revistas.urosario.edu.co/sociojuridicos/a.7543

Para citar: Feo Valero, J. (2019). Jurisdicción especial indígena, derecho colombiano y normativa internacional: la necesidad de un equilibrio en el marco de la extracción de minerales y el impacto de género. Revista Socio-Jurídicos, 21(2), 387-416. Doi: http://dx.doi.org/10.12804/revistas.urosario.edu.co/sociojuridicos/a.7543

\section{RESUMEN}

El presente artículo muestra el resultado del análisis jurídico efectuado sobre la relación existente entre la jurisdicción especial indígena, el derecho colombiano y la normativa internacional en el ámbito de la industria extractiva y el impacto de género. En este contexto, se propone una reflexión acerca de la igualdad de género y la extracción minera a la luz de la jurisdicción especial indígena, sus límites de acuerdo con la jurisprudencia nacional e internacional y la posibilidad de que la gestión de las actividades extractivas en territorios indígenas pudiera ser asumida por su jurisdicción. El artículo da cuenta de los principales problemas identificados en este ámbito, así como de la posición que hasta

* Artículo presentado en el marco del proyecto de investigación "Ressource extraction in Colombia with special attention to indigenous and gender perspectives" del Human Rights Research and Education Center (HRREC) de la Universidad de Ottawa. Financiado por el HRREC.

** Licenciado en Derecho y Doctor en Derechos Humanos, Democracia y Justicia Internacional (Rama Derecho Internacional) por la Universitat de València (España). Investigador Invitado y coordinador de Proyectos en el Human Rights Research and Education Center (HRREC) de la Universidad de Ottawa (Canadá). Proyecto financiado por el HRREC. Correo electrónico: jfeo@ uottawa.ca. ORCID: https://orcid.org/0000-0001-5584-5965. 
el momento han adoptado el tribunal constitucional de la República de Colombia y diferentes instancias internacionales.

Palabras clave: jurisdicción especial indígena, derechos de los pueblos indígenas, industria extractiva, mujeres indígenas, impacto de género.

\begin{abstract}
This article shows the result of the legal analysis on the relationship between special indigenous jurisdiction, Colombian law and international regulations in the framework of extractive industry and gender impact. In this context, researchers investigated gender equality and mining extraction from the perspective of the special indigenous jurisdiction, its limitations from the point of view of national and international jurisprudence and the possibility that it could assume the extractive activities carried out in indigenous territories. The article highlights the main problems identified in this area, as well as the position adopted so far by the constitutional court of the Republic of Colombia and different international bodies.
\end{abstract}

Keywords: Special indigenous jurisdiction, rights of indigenous peoples, extractive industry, indigenous women, gender impact.

\title{
RESUMO
}

O presente artigo mostra o resultado da análise jurídica efetuada sobre a relação existente entre a jurisdição especial indígena, o direito colombiano e a normativa internacional no âmbito da indústria extrativa e o impacto de gênero. Neste contexto, propõe-se uma reflexão acerca da igualdade de gênero e a extração mineira à luz da jurisdição especial indígena, seus limites de acordo com a jurisprudência nacional e internacional e a possibilidade de que a gestão das atividades extrativas em territórios indígenas pudesse ser assumida por sua jurisdição. $\mathrm{O}$ artigo dá conta dos principais problemas identificados neste âmbito, assim como da posição que até o momento têm adotado o tribunal constitucional da República da Colômbia e diferentes instâncias internacionais.

Palavras-chave: jurisdição especial indígena, direitos dos povos indígenas, indústria extrativa, mulheres indígenas, impacto de gênero. 


\section{Introducción}

El acuerdo de paz (en adelante Acuerdo) firmado en la República de Colombia en 2016 marcó un antes y un después en las cuestiones relacionadas con la igualdad de género y la gestión de los pueblos indígenas de sus territorios. Con el fin de consolidar el espíritu del Acuerdo, esta nueva realidad debería ir acompañada de un mayor protagonismo de la mujer en la toma de decisiones de la comunidad, así como de una mejora de la autonomía de los pueblos indígenas respecto de la gestión de los recursos naturales de sus territorios.

Resulta ilustrativo constatar que, de los cerca de treinta pueblos indígenas declarados en riesgo de extinción física y cultural en 2010, una veintena están afectados por la minería o la exploración minera (Human Rights Everywhere, 2011, p. 6). Diferentes investigaciones han demostrado cómo la minería genera impactos diferenciados entre hombres y mujeres (Jenkins, 2014, pp. 332-335); en Colombia, debido a las nuevas situaciones que se están produciendo tras la desmilitarización de determinadas zonas indígenas del país con intereses extractivos, esta cuestión ha adquirido especial relevancia.

En aras de poner de manifiesto la importancia de la igualdad género en el nuevo horizonte colombiano, es oportuno señalar que el Acuerdo entre el gobierno colombiano y el Frente Revolucionario Armado de Colombia (FARC) "reitera las obligaciones preexistentes del Estado en materia de derechos humanos" (Consejo de Derechos Humanos, A/HRC/37/3/ Add.3, 2018, párrafo 4).

En este sentido, el Estado está en la obligación de respetar, proteger y hacer efectivos todos los derechos humanos en el conjunto del territorio nacional, lo que implica asegurar su cumplimiento en las zonas más afectadas por el conflicto armado. Conviene resaltar de cara al presente trabajo que estas áreas de especial incidencia incluyen territorios indígenas con intereses extractivos en los que el Estado no siempre ha sido capaz de asegurar su presencia institucional, pero ha concedido, sin embargo, permisos de explotación minera (CPDH, diciembre 2015, p.109).

Es más, durante el 156 periodo de sesiones de la Comisión Interamericana de Derechos Humanos (CIDH) se denunció una nueva forma de invasiones territoriales llevadas a cabo a través de la presencia de 
corporaciones trasnacionales en territorios indígenas con el fin de proceder a la extracción de sus recursos naturales (Murua, 2018, p. 264).

A lo largo del texto, se analizan tanto el impacto de género en territorios indígenas con intereses extractivos a la luz de la jurisdicción especial indígena, como las lagunas existentes en materia de igualdad y sus límites, de acuerdo con la jurisprudencia nacional y la normativa internacional. Con el fin de realizar la exposición de manera clara, primeramente, se estudia cómo la actividad minera llevada a cabo por grandes corporaciones en territorios indígenas incide de forma diferente según el género. La igualdad de género y el respeto a los derechos humanos como principios rectores del ordenamiento jurídico colombiano en general, y de la jurisdicción indígena en particular, dará paso a un análisis de la jurisdicción especial indígena en concreto y su relación con los elementos presentados.

De este modo, el artículo sienta las bases para iniciar una reflexión acerca de la posibilidad de que la gestión de las actividades extractivas en territorios indígenas pudiera ser asumida por esa jurisdicción dentro del respeto a los estándares internacionales en materia de derechos humanos y de género que vinculan a la República de Colombia.

\section{El impacto diferenciado de la extracción de minerales sobre las mujeres en los territorios indígenas}

\section{La situación de las mujeres indígenas ante la falta de control efectivo del Estado sobre los territorios indigenas}

En 2006, la CIDH constató la situación de violencia a la que se veían sometidas las mujeres en situaciones de conflicto como consecuencia de la "lucha por controlar territorio y recursos económicos" (Comisión Interamericana de Derechos Humanos, OEA/Ser.L/V/II. Doc. 67, 2006).

La Corte Constitucional de la República de Colombia, dos años más tarde, identificó una serie de riesgos a los que las mujeres se ven sometidas por razón de género y que las transformaba en "víctimas de una espiral de agravación y profundización de la discriminación, exclusión y violencia de género que prevalecen de por sí en el paîs" (Corte Constitucional de Colombia, Auto 092/08, 2008). 
No debe olvidarse, que la población indígena femenina ha sido rehén de la pugna entre los diferentes actores del conflicto armado a través de los abusos que han padecido por razón de su género (Feo, 2019). Esta circunstancia las transformó en un elemento a través del cual se presiona a la comunidad indígena para plegarse a los dictados de componentes ajenos a la misma (Consejo Económico y Social, E/C.19/2011/3, 2011, párrafo 26).

Resulta pues evidente que las mujeres indígenas en Colombia se han visto afectadas de forma particular por la situación producida tanto durante el conflicto como tras la firma del Acuerdo en 2016 (Santos Calderón y Jiménez, 2016). Sin embargo, puede afirmarse que la visión de la mujer en el texto representa un punto de inflexión en la lucha por la igualdad de los géneros al incorporar "un enfoque de género y de interseccionalidad, sobre la base de los principios de igualdad y ejercicio efectivo progresivo" (Consejo de Derechos Humanos, A/HRC/34/3/Add.3, 2017, párrafo 11).

El Acuerdo recoge la necesidad de empoderar a las mujeres para que puedan participar en condiciones de igualdad con los hombres tanto en materia política como ciudadana. Para el Instituto Kroc de Estudios Internacionales de Paz, el enfoque de género en el Acuerdo constituye un hito en materia de construcción de paz a nivel internacional al ubicar los derechos de las mujeres y la igualdad de género en el centro del mismo (Instituto Kroc de Estudios Internacionales de Paz, 2017, p. 2) y comprometerse a actuar contra los problemas de ciertos colectivos históricamente marginados (Consejo de Derechos Humanos, A/HRC/34/3/Add.3, 2017, p. 3 ). Entonces, nos encontramos ante un documento de carácter progresista que contiene los mecanismos necesarios para abordar la discriminación estructural y el impacto del conflicto sobre las mujeres indígenas.

En el marco del posacuerdo, la Defensoría del Pueblo ha identificado el riesgo de violencia sexual en algunos Espacios Territoriales de Capacitación y Reincorporación (ETCR) por "situaciones de relacionamiento inapropiado entre los miembros de la Fuerza Pública y niñas, adolescentes y mujeres de las comunidades" (Defensoría del Pueblo de Colombia, Informe Espacios Territoriales de Capacitación y Reincorporación para la paz, 2017, p. 32). Por otro lado, la Comisión de Derechos Humanos de los Pueblos Indígenas determinó que entre 2015 y 2017 se reportaron 47 casos de delitos contra la libertad y la integridad sexual de las mujeres, 
lo que pone en evidencia la ausencia de denuncias públicas al respecto (2018, p. 10). La situación es alarmante, más si tenemos en cuenta que nos encontramos ante una realidad consolidada por el transcurso del tiempo a la que los diferentes gobiernos colombianos no han podido hacer frente de forma efectiva (Corte Constitucional de Colombia, Auto 266/17, 2017, párrafo 17).

De acuerdo con los datos disponibles en el Registro Único de Víctimas, entre 1985 y 2018 un total de 104.991 mujeres sufrieron algún tipo de violación de sus derechos humanos (Registro Único de Víctimas, 2018). La disparidad de datos entre los casos de delitos contra la libertad y la integridad sexual y las denuncias realizadas por diferentes organismos internacionales acerca de la situación de las mujeres indígenas en zonas de conflicto viene a corroborar lo manifestado por el ECOSOC en 2011 respecto a las pocas investigaciones que finalmente se llevan a cabo en este ámbito (E/C.19/2011/3, 2011, párrafo 26).

En este mismo sentido, el informe presentado al Comité de la CEDAW de Naciones Unidas en 2013 confirmaba la existencia de "patrones discriminatorios en razón del sexo en el sistema judicial, que impiden el acceso a la justicia para las mujeres" (Alianza Iniciativa de Mujeres Colombianas por la Paz (IMP); Asociación Colectivo Mujeres al Derecho; Casa de la Mujer; Católicas por el Derecho a Decidir, Colombia; Centro de Estudios de Derecho, Justicia y Sociedad (Dejusticia); Centro de Investigación y Educación Popular / Programa por la Paz..., 2013, p. 16). Llama la atención como, de las investigaciones por violencia intrafamiliar, violencia sexual y homicidios contra mujeres por el hecho de ser mujeres que se llevaron a cabo entre los años 2009 y 2012, en más del $85 \%$ de los casos no pudo determinarse la autoría (Quintero Benavides, 2013, p. 60). La En 2015, la relatoría sobre los derechos de los pueblos indígenas identificó el hecho de que la violencia continuada a la que se han visto sometidas las mujeres indígenas ha provocado su "victimización en ciertas zonas del país señaladas por las realidades de las circunstancias de su vida cotidiana y su sistemática exclusión del goce de los derechos y recursos garantizados a otros ciudadanos" (Asamblea General, A/HRC/30/41, 2015, párrafo 46).

Victoria Tauli Corpuz, por su lado, en el marco de conflictos en el que están implicados agentes empresariales, y mencionando concretamente el caso de Colombia, denunció que "las mujeres y niñas indígenas 
sufren regularmente situaciones de violación, prostitución forzada y explotación en el contexto de la ocupación de tierras indígenas" (Asamblea General, A/ $\mathrm{HRC} / 30 / 41,2015$, párrafo 53).

En el caso de Colombia, las mujeres indígenas han sufrido un doble impacto como consecuencia de los problemas causados por las lagunas en materia de gobernabilidad institucional y por la explotación minera (Tribunal Permanente de los Pueblos, 2014, p. 40).

\section{La problemática de la industria minera en las mujeres indígenas}

El Consejo Económico y Social de las Naciones Unidas (ECOSOC), en su informe del año 2011 resaltó la relación existente entre la agresión sexual y de violencia de género y el control de los recursos extractivos. Este organismo hizo eco de la falta de protección de las mujeres indígenas frente a estas conductas y de cómo, una vez que se identificaban los hechos, pocas veces se llevaban a cabo investigaciones pertinentes (E/C.19/2011/3, 2011, párrafo 26).

Una vez controlado el territorio y garantizadas las concesiones a grandes empresas del sector extractivo, surgen nuevas realidades en el seno de los territorios indígenas. Cabe destacar el aumento del número de residentes temporales de la zona indígena en cuestión, a la que se traslada mano de obra en busca de oportunidades para desarrollar actividades relacionadas con la explotación de minerales. Se genera, de este modo, un desequilibrio entre los habitantes originales y los nuevos moradores. La minería, si bien puede contribuir al desarrollo de las comunidades, al proveer empleo y servicios a las poblaciones indígenas de las zonas donde se implantan, puede así mismo hacerlas más vulnerables al generar nuevas realidades, necesidades y obligaciones.

La explotación de recursos naturales a gran escala en las zonas rurales indígenas suele implicar un cambio en el modo de vida de los moradores de esos territorios (Jenkins, 2014, p. 335) que afecta de manera especial al rol tradicional desempeñado por las mujeres en el seno de la comunidad.

Las situaciones generadas por los intereses extractivos en territorios indígenas tienen un impacto diferenciado entre hombres y mujeres. Los procesos de intervención, por ejemplo, tienden a ser arbitrarios, ya que 
las negociaciones suelen producirse "con los hombres de las comunidades sin respetar los procesos propios de toma de decisiones, lo que genera que no haya oportunidad de que las mujeres puedan participar mediante asambleas comunitarias" (CIDH, OEA/Ser.L/V/II., Doc. 47/15, 2015, p. 177). Además, de acuerdo con la $\mathrm{CIDH}$, la extracción de recursos naturales en zonas indígenas ha creado un "patrón de discriminación y diversas formas de violencia específicas" (OEA/Ser.L/V/II., Doc. 47/15, 2015, pp. 11 y 175).

En 2013, la Comisión Interamericana de Derechos Humanos, en el marco de la "Audiencia sobre la situación de derechos humanos de los pueblos indígenas en Colombia" pudo constatar a través de diversos testimonios, cómo el desarrollo de actividades por parte de las grandes explotaciones llevaban aparejadas, en numerosas ocasiones, un incremento de casos de violencia sexual y física, redes de trata de personas y prostitución forzada ( $\mathrm{CIDH}, 2013$ ). Estas circunstancias provocan el desplazamiento de las poblaciones de los Resguardos Indígenas como consecuencia de su oposición a los proyectos extractivos (Comisión de Derechos Humanos de los Pueblos Indígenas, 2018, p. 13).

Por otro lado, el hecho de que los hombres se pongan a trabajar en las empresas mineras implica que las mujeres se vean obligadas a cambiar sus costumbres y patrones de comportamiento respecto de las obligaciones y responsabilidades que desarrollaban en el seno de la comunidad y el núcleo familiar (CIDH, 2012). La ocupación por las empresas mineras de los territorios indígenas, no solo dificulta el acceso a los recursos y a las tierras necesarias para la explotación agro-pecuaria, impidiéndoles de este modo desarrollar sus funciones familiares, sino que suele conllevar una feminización de la pobreza, debido a la falta de oportunidades de empleo, las precarias condiciones laborales y la sobrecarga de trabajo del cuidado de los hijos (Barón Romero, 2013). Es frecuente que personas ajenas a la comunidad indígena entablen relaciones con las mujeres y renuncien, en su caso, a hacerse cargo de los nuevos nacimientos que puedan acontecer, descargando la responsabilidad de su cría y educación sobre las madres. Esta conjunción de factores puede empujar a las mujeres a abandonar sus tierras y trasladarse a zonas urbanas en busca de un sustento para sus familias. Allí, los trabajos que desarrollan suelen estar poco cualificados, viéndose en ocasiones obligadas a ejercer la prostitución (CIDH, 2012). 
De la información recabada se puede concluir que la actividad minera a gran escala en Colombia ha dejado profundos impactos en las mujeres indígenas, entre los que destacarían:

la sobrecarga del trabajo de las mujeres por la ausencia del esposo; las responsabilidades que deben asumir a causa de familias afectadas por la defensa de las tierras y territorios, como el caso de niños y niñas huérfanos por la muerte de dirigentes; la trata de mujeres y niñas indígenas en los asentamientos mineros y petroleros; el incremento del alcoholismo en las comunidades por personas ajenas a la comunidad; la violación de niñas y mujeres; niños y niñas sin padre producto de violaciones [...]; debilitamiento de la vida comunitaria y familiar. (CIDH, 2015, p. 176)

En el contexto de intereses cruzados sobre el control, gestión y explotación de los recursos mineros, las mujeres han sido víctimas de las corporaciones con intereses extractivos en sus tierras ancestrales (Simons, 2017, p. 418). La población femenina indígena en Colombia ha sido víctima de violaciones de derechos en aquellos territorios con potencial minero en los que se han producido lagunas en materia de gobernabilidad derivadas tanto del conflicto armado como de la ausencia de autoridad estatal sobre el terreno. Con el paso de los años, esta situación no solo se ha consolidado, sino que se ha convertido en un problema estructural. De acuerdo con James Anaya, ${ }^{1}$ a esta situación debe hacerse frente con programas elaborados específicamente para combatir la violencia contra las mujeres y las niñas, a fin de que puedan resolverse los problemas estructurales de los pueblos indígenas que contribuyen a la violencia de género (Consejo de Derechos Humanos, A/HRC/21/47, 2012, párrafo 27).

1 El Sr. James Anaya fue Relator especial sobre los derechos de los pueblos indígenas entre los años 2008 y 2014. 


\section{La necesidad de hacer de la igualdad de género y los derechos humanos elementos rectores de la jurisdicción especial indígena}

A lo largo de la historia ha podido constatarse una marginalización de las mujeres indígenas a la hora de participar en la toma decisiones de la comunidad. Esto se debe principalmente a la existencia de una mentalidad patriarcal entre las comunidades indígenas y al rol tradicional que han jugado las mujeres en su seno en Colombia (Bruno, 2017; Bouvier, 2016).

Es importante destacar que la autonomía de estas comunidades indígenas encuentra su límite en las fronteras de su territorio ancestral (Ariza, 2004, p. 64), así como en el necesario respeto de las autoridades e instituciones indígenas a los estándares internacionales que en materia de género y derechos humanos hayan sido asumidos por $\mathrm{Co}^{-}$ lombia. La Corte Constitucional de Colombia ha incidido en este punto al recordar a las autoridades colombianas su obligación de respetar y hacer respetar las obligaciones derivadas del derecho internacional (Auto 092/08, 2008).

En opinión del autor, este hecho conlleva no solamente la necesidad de respetar estos parámetros, sino de fomentarlos e integrarlos en el sistema jurídico sobre el que se apliquen. La Corte Constitucional de Colombia ha recordado a las autoridades colombianas su obligación de respetar y hacer respetar las obligaciones derivadas del derecho internacional, entre los que se incluyen los referidos a los derechos humanos, en tanto que legislación aplicable en el país (Auto 092/08, 2008).

De acuerdo con la Corte Constitucional de Colombia, las regulaciones del Convenio 169 de la Organización Internacional del Trabajo (OIT, Convenio 169, 1989) y la Declaración de las Naciones Unidas sobre los Derechos de los Pueblos Indígenas de 2007 (UNDRIP) (Asamblea General, A/RES/61/295, 2007) forman un bloque de constitucionalidad cuya vulneración puede ser motivo de tutela en cuanto afecten derechos fundamentales. Además, la UNDRIP constituye "una pauta de interpretación de los derechos de las personas y los pueblos aborígenes, que debe ser tenida en cuenta por el juez constitucional" (Corte Constitucional de Colombia, Sentencia SU-510/98, 1998; Sentencia T-606/01, 2001 y Sentencia T-617/10, 2010). En este sentido, la Magistrada Garzón de 
Gómez, en su análisis sobre el conflicto positivo entre la jurisdicción ordinaria penal y la indígena estableció que "en este panorama, los principios del Estado Social de Derecho y la axiología superior de los derechos humanos, todas las etnias, los pueblos y los hombres se conciben iguales en dignidad y derechos" (Corte Constitucional de Colombia, Radicación No. 11001010200020160365700 [12420-31], 2017).

Así pues, de acuerdo con el artículo 3 del convenio 169, los pueblos indígenas, integrados por hombres y mujeres, tienen derecho a gozar en igualdad de oportunidades de los derechos humanos y libertades fundamentales. El artículo 8 del convenio matiza el alcance de los derechos de los que hombres y mujeres indígenas son sujetos pasivos, cuando establece que los pueblos indígenas tienen derecho a "conservar sus costumbres e instituciones propias, siempre que éstas no sean incompatibles con los derechos fundamentales definidos por el sistema jurídico nacional ni con los derechos humanos internacionalmente reconocidos" (OIT, 1989, artículos 3 y 8). Por lo tanto, si los pueblos indígenas tienen derecho a conservar sus instituciones de acuerdo con estos límites, los mismos les deberán ser de aplicación individualmente sin que el género pueda suponer un factor de discriminación.

Por otro lado, la UNDRIP incide en que los sistemas jurídicos de las comunidades indígenas deberán ser acordes con los estándares internacionales en materia de derechos humanos. Así mismo, conscientes de la discriminación de las que son víctimas las mujeres indígenas, el texto hace un llamamiento a los Estados para que, en colaboración con las comunidades indígenas, aseguren "que las mujeres y los niños indígenas gocen de protección y garantías plenas contra todas las formas de violencia y discriminación" (Asamblea General, A/RES/61/295, 2007, artículos 22 y 34). El Relator Especial sobre la situación de los derechos humanos y las libertades fundamentales de los indígenas, en su informe $\mathrm{E} /$ CN.4/2006/78, pidió a los países que se adoptaran "medidas y acciones concretas que ayuden a cerrar la brecha existente entre las legislaciones para la protección de los derechos humanos de los indígenas y su implementación efectiva" (Consejo Económico y Social, 2006, p. 23), lo que conlleva la protección de las mujeres y su igualdad ante la ley.

La previsibilidad de las autoridades indígenas a la hora de llevar a cabo sus actuaciones constituye un elemento esencial para garantizar 
la legalidad y el debido proceso. Esta característica conlleva el cumplimiento de reglas y procedimientos de acuerdo "con la especificidad de la organización social, política y jurídica de la comunidad de que se trate, así como los caracteres de su ordenamiento jurídico" (Corte Constitucional de Colombia, Carlos Gaviria Díaz, Sentencia T349/96, 1996). Las normas tradicionales que fundamentan sus decisiones no deberían discriminar por razón de género en base a sus costumbres ancestrales, ya que las mismas son susceptibles de evolución conforme a las nuevas circunstancias y realidades que se puedan producir.

De esta interpretación jurisprudencial subyacería el hecho de que el legislador, de forma velada, podría estar sugiriendo a las comunidades indígenas la necesidad de adaptar sus normas e instituciones a la igualdad entre hombres y mujeres en los diferentes ámbitos de la vida comunitaria, de acuerdo con las estipulaciones recogidas en la normativa sobre derechos humanos internacionalmente reconocida.

Así mismo, se ha establecido que los derechos fundamentales de los integrantes de la comunidad representan una limitación al libre albedrío de sus autoridades. En 1998, la Corte Constitucional de Colombia aceptó limitar la autonomía de las autoridades indígenas siempre que el bien jurídico a proteger lo integrara "el núcleo esencial de los derechos fundamentales de los miembros de la comunidad" (Sentencia SU-510/98, 1998).

Conviene plantearse si el límite a la autonomía de los pueblos indígenas debería constituirlo la totalidad de los derechos fundamentales, tal y como sostiene este autor $\mathrm{y}$, al parecer, los tratados y convenios internacionales ratificados por el Estado colombiano. En este sentido, la Corte Constitucional de Colombia ha mostrado ambigüedad al indicar que, si bien los derechos fundamentales de los miembros de la comunidad indígena representan una limitación frente a decisiones arbitrarias, el conflicto habrá de resolverse mediante la herramienta de la ponderación de principios (Sentencia T-201/16, 2016). Dicha ponderación consistiría en evaluar "los criterios dentro de los cuales la limitación o restricción de un derecho resulta legítima por lograr una mayor eficacia de otro $u$ otros derechos constitucionales" (Corte Constitucional de Colombia, Sentencia T-617/10, 2010). Por otro lado, sería conveniente llevar a cabo dicha ponderación desde un enfoque multicultural que permitiera comparar el "objeto por 
proteger y el medio o impacto sobre el sujeto individual o colectivo de esa protección" (Sánchez Botero, 2009, p. 47).

\section{La jurisdicción especial indígena en el marco de la industria extractiva en Colombia}

\section{Relación entre la jurisdicción especial indígena y la jurisdicción ordinaria}

En Colombia, la Constitución, a través de su artículo 246, reconoce el derecho de los pueblos indígenas a desarrollar su propia jurisdicción. Este precepto conlleva que las diferentes comunidades pueden, de acuerdo con sus normas y costumbres ancestrales, implementar "sus propios sistemas de autoridad, control social y resolución de disputas" (De la Cruz I., 2006, p. 12). Es importante matizar que no se trata de una jurisdicción homogénea en la que las diferentes entidades tribales se rigen por una misma regulación normativa, sino que pueden existir tantas jurisdicciones y normas como comunidades indígenas. En este sentido, Libardo Ariza, defiende que los pueblos indígenas "deben ser diferenciados para no caer en la tentación homogeneizadora del pasado" (Ariza, 2004, p. 85). Puede decirse, por lo tanto, que lo que realmente existe no sería tanto un derecho indígena, sino un "derecho propio por cada pueblo" (Sánchez Botero, 2005, p. 227).

El conjunto normativo internacional que sirve de base para este reconocimiento lo constituyen el Convenio 169, la UNDRIP y el Convenio de Diversidad Biológica, ratificados por Colombia en la Ley N ${ }^{\circ} 21$ de 1991 y la Ley $N^{\circ} 165$ de 1994. De acuerdo con el anterior Relator especial sobre los derechos de los pueblos indígenas, James Anaya, los derechos consagrados en la UNDRIP están concebidos para remediar el legado persistente de discriminación contra los pueblos indígenas (Consejo de Derechos Humanos, A/HRC/21/47, 2012, párrafo 27).

El artículo 2 del Convenio 169 establece la obligación de los gobiernos vinculados por el convenio a "desarrollar con la participación de los pueblos interesados una acción coordinada y sistemática con miras a proteger los derechos de esos pueblos y a garantizar el respeto de su 
integridad...asegurando la igualdad, la plena efectividad de los derechos de una manera compatible con su forma de vida" (OIT, 1989, art. 2).

A la hora de analizar la coordinación necesaria entre la jurisdicción especial indígena y la jurisdicción ordinaria en Colombia debería tenerse en cuenta que, de acuerdo con lo reconocido por pueblos indígenas, algunos conflictos internos pueden tener mejor solución en la jurisdicción ordinaria (Sánchez Botero, 2005, p. 229), por lo que no habría que descartarse per se que determinadas situaciones pudieran ser analizadas desde la perspectiva de la jurisdicción ordinaria si las comunidades indígenas afectadas estuvieran de acuerdo.

Dicho lo anterior, el problema principal a la hora de articular la coordinación entre ambas jurisdicciones se encuentra en la falta de normativa que establezca claramente los ámbitos y situaciones en los que se aplica o prevalece una jurisdicción sobre la otra. A día de hoy, y a pesar de que la Constitución de 1991 lo recoge expresamente en el artículo 246, aún no se han establecido por Ley "las formas de coordinación de esta jurisdicción especial con el sistema judicial nacional". Esta falta de claridad ha provocado que, a la hora de dar respuesta a asuntos en los que confluyen ambas jurisdicciones, tanto las autoridades indígenas como los funcionarios del estado realicen "interpretaciones erróneas sobre la garantía de los derechos humanos y las transgresiones de alcances y límites" (Cruz, 2017, p. 5).

El Consejo Superior de la Magistratura, en aras de dar solución a estos conflictos de competencia, ha expedido una serie de acuerdos que pretenden mejorar la coordinación entre ambas jurisdicciones. El Acuerdo PSAA12-9614 de 2012 (Consejo Superior de la Judicatura, 2012) creó la Comisión Nacional de Coordinación de la Jurisdicción Especial Indígena y el Sistema Judicial Nacional, mientras que el Acuerdo PSAA13-9816 de 2013 (Consejo Superior de la Judicatura, 2013) hizo lo propio con las Mesas Departamentales Interjurisdiccionales en tanto que mecanismos regionales de coordinación. Por su lado, el artículo 11 de la Ley Estatutaria de la administración de justicia reconoce a las Autoridades de los Territorios Indígenas como parte de la Rama Judicial del Poder Público, mientras que el artículo 12 matiza que únicamente podrán ejercer la jurisdicción "en el ámbito de su territorio y conforme a sus propias normas 
y procedimientos, los cuales no podrán ser contrarios a la Constitución y a las Leyes" (Ley 270 de 1996).

En palabras de la Defensoría del Pueblo de Colombia, el reconocimiento de la jurisdicción especial indígena implica la posibilidad, por parte de las autoridades de los territorios indígenas, de resolver los conflictos "que se produzcan en el interior de su ámbito territorial de acuerdo a sus propios procedimientos, usos y costumbres" (2014, Boletín no 6).

De acuerdo con la Sentencia No. C-139/96 de la Corte Constitucional de Colombia, cuatro son los elementos esenciales que componen la jurisdicción especial indígena, a saber: la existencia de autoridades propias de los pueblos indígenas; su potestad para establecer normas y procedimientos propios a los miembros de su colectividad en sus territorios, la sujeción de dicha jurisdicción y normas a los principios de la Constitución y las leyes, y la coordinación de la jurisdicción indígena con el sistema judicial nacional (1996).

EN 2012, el Mecanismo de Expertos sobre los Derechos de los Pueblos Indígenas de la ONU (MEDPI) reconoció que tanto sus sistemas de justicia como la práctica de los mismos forman parte de la cultura de los pueblos indígenas (A/HRC/21/53, 2012, párrafo 21). Un año más tarde, este mismo organismo dejaba patente que el acceso a la justicia formaba, así mismo, parte de sus derechos culturales (A/HRC/24/50, 2013, párrafo 28). En 2017, la “Opinión 10: el ámbito empresarial y el acceso a servicios financieros para los pueblos indígenas" pedía a los Estados que adoptaran "marcos jurídicos y de políticas que reconozcan, promuevan y protejan derechos que permitan a los pueblos indígenas que así lo deseen operar empresas en sus tierras de manera segura y viable" (MEDPI, 2017, párrafo 1).

De acuerdo con la Defensoría del Pueblo, la jurisdicción especial indígena podría aplicarse a otros ámbitos de la vida de las comunidades indígenas ya que "tiene un alcance amplio que faculta a sus autoridades para actuar en otros ámbitos de la vida política, administrativa y jurídica relacionados con sus asuntos internos, frente a la comunidad y su territorio" (Defensoría del Pueblo de Colombia, 2014, Boletín No 6, p. 2). Esta afirmación no es baladí, ya que, de interpretarse en este sentido, se abriría la puerta a que las comunidades indígenas pudieran regular sus 
propios procedimientos administrativos de concesión de explotaciones mineras en sus territorios. Además, su aplicación podría extenderse a personas que no pertenecieran a la comunidad indígena de que se trate siempre que se viese afectado el interés general de la comunidad o de su territorio.

\section{Las competencias en materia de minería en el marco de la jurisdicción especial indígena}

Hemos de iniciar este apartado haciendo referencia al artículo 332 de la Constitución, el cual establece que "el Estado es propietario del subsuelo y de los recursos naturales no renovables, sin perjuicio de los derechos adquiridos $y$ perfeccionados con arreglo a las leyes preexistentes".

Sin entrar en el fondo del tema sobre la soberanía de los recursos naturales en Colombia, conviene mencionar la Sentencia C-123/14 de la Corte Constitucional de Colombia en la que se señala que "una autorización al respecto [realización de actividades de exploración y explotación mineral deberá dar la oportunidad de participar activa y eficazmente a las entidades municipales o distritales involucradas en dicho proceso, mediante acuerdos sobre la protección de cuencas hídricas y la salubridad de la población, así como, del desarrollo económico, social y cultural de sus comunidades" (2014, p. 56). El juez ponente fundamenta la cuestión en los principios constitucionales de autonomía territorial y de descentralización administrativa (Constitución, 1991, artículos 287 y 288) y que son de aplicación a las entidades territoriales reconocidas en el artículo 286.

El Comité para la Eliminación de la Discriminación Racial (CERD), ya en 1997 recomendó a los Estados, a través de su Recomendación General $\mathrm{N}^{\mathrm{o}}$ XXIII, que reconocieran el derecho de los pueblos indígenas a "poseer, explotar y controlar los territorios que han ocupado tradicionalmente, en particular los recursos hídricos y subterráneos" (1997, párrafo 5). En 2015 solicitó expresamente al gobierno de Colombia que garantizara "el goce pleno y efectivo de los derechos de los pueblos indígenas y afrocolombianos sobre las tierras, territorios y recursos naturales que ocupan o usan, frente a actores externos que explotan los recursos naturales tanto legal como ilegalmente" (CERD, 2015, párrafo 24). 
La Corte Constitucional de Colombia ha hecho suyas las interpretaciones del Comité de Derechos Económicos, Sociales y Culturales respecto del artículo 1 del Pacto Internacional de Derechos Civiles y Políticos y del Pacto Internacional de Derechos Económicos, Sociales y Culturales en cuanto a que, "el derecho de los pueblos indígenas a controlar los recursos naturales dentro de sus territorios está asociado con el derecho a la libre determinación. Del mismo modo, la propiedad y el uso de recursos naturales está ligado con el derecho al goce de la propia cultura" (Sentencia T-530/16, 2016). Este organismo es consciente de las "tensiones con otros principios constitucionales de la sociedad mayoritaria" (Sentencia T-601/11, 2011) que puede generar el hecho de que las comunidades indígenas apliquen y desarrollen su propia normativa basada en una concepción del mundo y del desarrollo diferente a la opinión mayoritaria.

El Tribunal Constitucional ha hecho una referencia muy interesante para el caso que nos ocupa al recordar que el principio de autonomía de los pueblos indígenas conlleva "la organización política de las comunidades, así como en el manejo de sus asuntos, entre los que se destaca la posibilidad de concebir y manejar un concepto propio de desarrollo, definir sus prioridades y planes económicos" (Sentencia T-601/11, 2011, nota al pie $n^{\circ} 61$ ).

En 2017, la propuesta de Plan de Acción sobre la jurisdicción especial indígena interpretó que, a la luz del artículo 246 de la Constitución, "la autonomía otorgada a las comunidades indígenas se extiende no sólo al ámbito jurisdiccional sino también al legislativo, en cuanto incluye la posibilidad de creación de normas y procedimientos" (Consejo Superior de la Judicatura, Propuesta de plan de acción 2017, 2017). Esta interpretación podría permitir que las comunidades indígenas llevaran a cabo un desarrollo procedimental respecto de la concesión de licencias de explotación en sus territorios, en las que se integraría la explotación minera. Además, hay que tener en cuenta que, a la hora de tratar un posible conflicto normativo entre las normas indígenas y la constitución, la Corte Constitucional de Colombia estima que ambas deben ser consideradas como "normas constitucionales de igual jerarquía" (Sentencia T-601/11, 2011).

Por su parte, el Código de Minas, entiende como territorios indígenas "las áreas poseídas en forma regular y permanente por una comunidad, parcialidad o grupo indígena de conformidad con lo dispuesto en la Ley 
21 de 1991 y demás leyes que la modifiquen, amplíen o constituyan" (Congreso de Colombia, Ley 685 de 2001, artículo 123).

La concesión a una comunidad indígena dentro de una zona de explotación en su territorio se concede a "solicitud de la comunidad o grupo indígena y en favor de esta y no de las personas que la integran". En estas circunstancias, se ha considerado oportuno dotar a las comunidades indígenas de cierta autonomía al permitir a la autoridad indígena que sea ella la que determine "la forma como estas participen en los trabajos mineros y en sus productos y rendimientos y las condiciones como puedan ser sustituidas en dichos trabajos dentro de la misma comunidad" (Congreso de Colombia, Ley 685 de 2001, artículo 125).

Llegados a este punto resulta muy interesante constatar cómo el legislador se ha dotado de una cláusula de seguridad para evitar que la jurisdicción indígena regule la minería, prohibiendo en cualquier supuesto la transferencia de la concesión. De no haber sido así, podría darse la situación de que las comunidades indígenas solicitaran en su nombre concesiones en sus territorios, las regularan conforme a sus propias normas y procedimientos y las transfirieran a terceros con la condición de que estos se rigieran por la jurisdicción indígena y no por la ordinaria. La cuestión que subyace por tanto es determinar si, en una situación de este tipo, el Código de Minas tendría una prelación normativa sobre la autonomía territorial y la jurisdicción indígena; es más, habría que analizar en qué supuestos los intereses económicos son más importantes que las prerrogativas constitucionales que se otorgan a los pueblos indígenas.

La duda sobre la legalidad de la aplicación del Código de Minas a la población indígena en sus territorios ha sido puesta de relieve por diferentes asociaciones. En este sentido, la organización Forest Peoples Programme, en su Amicus Curiae ante la Corte Constitucional de Colombia, indicó que "las disposiciones del Código de Minas que pretenden hacer titular al Estado colombiano de todos los recursos del subsuelo podrían ser susceptibles de constituir una violación a la normatividad internacional, al no tener en cuenta el derecho de propiedad de los pueblos indígenas sobre sus territorios" (Sentencia T-530/16, 2016).

De acuerdo con lo establecido por la Corte Interamericana de Derechos Humanos, el concepto de territorio de los pueblos indígenas debe incluir tanto la superficie territorial como el subsuelo (Corte IDH, Caso 
de los Pueblos Indígenas Kuna de Madungandí y Emberá de Bayano y sus Miembros Vs. Panamá, 2014, párrafo 111). La jurisprudencia interamericana reconoce que la participación de las comunidades indígenas en los proyectos mineros que se desarrollen o tengan impacto sobre sus territorios debe llevarse a cabo de conformidad con las costumbres y tradiciones de los pueblos indígenas (Corte Interamericana de Derechos Humanos, Caso del Pueblo Saramaka vs. Surinam, 2007). En este sentido, la Sentencia No. T-254/94, de la Corte Constitucional de Colombia, "fundamenta la prevalencia de los usos y costumbres en la materia sobre normas que sólo deben tener aplicación en ausencia de una autoregulación por parte de las comunidades indígenas" (1994).

\section{La autonomía indígena y sus límites}

En el análisis de la autonomía indígena y sus límites dentro del ámbito normativo colombiano, resulta conveniente referirse previamente a la cuestión de la consulta previa, y del consentimiento libre e informado en la medida en que constituye una manifestación de gran relevancia de la autonomía indígena garantizada por el derecho internacional. Como ya se ha mencionado, Colombia, en tanto que firmante de determinados convenios y tratados internacionales, se ve vinculada por las estipulaciones que de ellos se derivan.

El derecho a la consulta previa deriva del derecho de los pueblos indígenas a la auto-determinación (Grupo de Naciones Unidas para el Desarrollo, 2009, p. 14). Tanto la Declaración de la ONU sobre Pueblos Indígenas como el Art. 6 del Convenio 169 de la orT, establecen que "la consulta deber ser realizada por medios idóneos, de buena fe y con instituciones representativas de los pueblos indígenas y tribales" (Amicus Curiae 2015, p. 17).

Puede afirmarse que, "la consulta previa es un derecho humano de los pueblos indígenas reconocido por la ONU, cuyo contenido ha sido progresivamente desarrollado para incluir los elementos libres e informados, lo cual ha sido consolidado en el Art. 19 de la Declaración de la ONU sobre Pueblos Indígenas" (Amicus Curiae, 2016, p. 16).

Su propósito es garantizar que los pueblos indígenas dispongan de los elementos necesarios para la asegurar su autonomía a través de la toma de decisiones de acuerdo con sus creencias e intereses. 
Ya en el ámbito nacional colombiano, la Constitución no deja lugar a dudas respecto de la consideración de los territorios indígenas como entidades territoriales que gozan de autonomía para la gestión de sus intereses (Corte Constitucional de Colombia, Sentencia C-889 de 2012, 2012), por lo que las autoridades indígenas deberían ser competentes en todo aquello que les faculta el principio constitucional de autonomía territorial (Samuel Baena, 2015, p. 117) y el reconocimiento de la jurisdicción especial indígena.

El artículo 329 de la Constitución de la República de Colombia establece la obligación de aprobar una ley especial que "reglamente lo relativo a la conformación de las Entidades Territoriales Indígenas" de acuerdo con Ley Orgánica de Ordenamiento Territorial. A este respecto existen dos problemas principales; el primero es que la Ley Orgánica de Ordenamiento Territorial no recoge a las entidades territoriales indígenas en el reparto de competencias establecido en su artículo 29 (República de Colombia, 2011). El segundo es que, hasta el momento, la ley relativa al desarrollo de estas entidades nunca se ha aprobado, por lo que existe un vacío legal al respecto que debería ser asumido por la jurisprudencia constitucional.

En 2014, el Decreto 1953 entró a regular la autonomía de los pueblos indígenas hasta que el Congreso de Colombia no legisle al efecto (Decreto, 1953, 2014, artículo 1), a través de la creación de un régimen especial para territorios indígenas. Las discusiones en torno al Decreto 1953 se han centrado principalmente en el hecho de si ha contribuido efectivamente a la autonomía de estos territorios. De acuerdo con Linares, "existe una clara divergencia entre la manera como el Estado entiende la autonomía y el desarrollo y la manera como los indígenas perciben estos conceptos, lo que, per se, supone una insuficiencia en el alcance del Decreto 1953 de 2014" (2016, p. 25).

Por su parte, el Decreto 632 de 2018 reconoce la autoridad de las organizaciones indígenas sobre más de 18 millones de hectáreas en las que no había autoridades locales de los departamentos de Amazonas, Guainía y Vaupés. El Decreto queda limitado a estas zonas, al tratarse de los únicos departamentos del país donde hay áreas no municipalizadas. La norma establece los pasos a seguir para delimitar los territorios (Decreto 632,2018 , art. 12), lo que podría servir de modelo de referencia para futuros procesos. 
Los límites a esta jurisdicción están establecidos por el mismo artículo constitucional que faculta su desarrollo. De acuerdo con este precepto, podrán ejercer su jurisdicción "de conformidad con sus propias normas y procedimientos, siempre que no sean contrarios a la Constitución y leyes de la República" (Constitución de la República de Colombia, 1991, art. 246).

Por su lado, la jurisprudencia de la Corte Constitucional de Colombia establecida en la Sentencia T-601/11, estableció que la autonomía de las comunidades indígenas únicamente podrá ser restringida si la decisión a implementar tiene como fin salvaguardar un interés de mayor jerarquía y no existe ninguna alternativa con menor impacto sobre su autonomía. (2011, notas al pie 67 a 70).

El problema que se plantea en este supuesto es determinar qué se entiende por interés de mayor jerarquía y cómo se determina. En este punto, la jurisprudencia no es clara al respecto, ya que establece que deberá llevarse a cabo teniendo en cuenta las particularidades de cada comunidad. Si la decisión implica únicamente a miembros de una misma comunidad, mayor será el grado de autonomía del que se goza, de acuerdo con sus propios criterios y costumbres. La Sentencia T-349/96 consideró que los límites al principio de maximización de la autonomía únicamente pueden verse afectados si se vulneran una serie de derechos intangibles que incluirían el derecho a la vida, la prohibición de la esclavitud y la prohibición de la tortura (Corte Constitucional de Colombia, 1996). Ese mismo año, la Sentencia C-139/96 estableció que la jurisdicción especial indígena debía integrar "la facultad de las comunidades de establecer autoridades judiciales propias; la potestad de establecer y/o conservar normas y procedimientos propios; la sujeción de los elementos anteriores [(i) y (ii)] a la Constitución y la ley; la competencia del legislador para señalar la forma de coordinación ínter jurisdiccional".

Además, en aras de garantizar la seguridad jurídica, habrá que diferenciar entre las comunidades indígenas que conservan sus normas y tradiciones de aquellas que no lo hacen. Esto es así porque el legislador quiere asegurar que todos los individuos estén sujetos al imperio de la ley, ya sea a través de la jurisdicción especial indígena o de la legislación ordinaria. La Sentencia T-254 de 1994, diferencia entre los grupos indígenas que conservan en mayor medida sus usos y costumbres de aquellos que no lo 
hacen, lo que implica que a los segundos se les aplique en mayor medida la jurisdicción ordinaria (Corte Constitucional de Colombia, 1994).

El problema que se plantea al respecto es determinar si todo aquello que no esté contemplado por la jurisdicción especial indígena ha de ser objeto de regulación por la jurisdicción ordinaria o si la comunidad, adaptándose a las nuevas circunstancias que se vayan produciendo con el transcurso del tiempo, podría regular de acuerdo a sus usos y costumbres.

Este autor considera que, si se opta por una interpretación restrictiva, el desarrollo de la comunidad se verá limitado al no permitírseles evolucionar de acuerdo a sus propias decisiones y prioridades, y acabarán estandarizando muchos aspectos de su vida actual con el resto de población no indígena. Sea como fuere, resulta necesario que se respete el principio de legalidad en el procedimiento y el de legalidad de los delitos y de las penas, "lo que presupone la existencia de las mismas con anterioridad al juzgamiento de las conductas" (Corte Constitucional de Colombia, Sentencia T349/96, 1996).

La aclaración respecto de la problemática que se plantea parece encontrar respuesta en las Sentencias T-601/11 y T-514/12, al establecerse que el mayor o menor grado de conservación cultural por parte de una comunidad indígena "no puede llevar a ningún operador judicial, a desconocer las decisiones autónomas de cada comunidad, incluidas aquellas dirigidas a iniciar un proceso de recuperación de tradiciones o a separarse de algunas".

\section{Conclusiones}

A lo largo del presente trabajo hemos constatado el impacto que sobre las mujeres indígenas han generado en Colombia las grandes explotaciones de los recursos naturales en sus territorios. A pesar de que el Acuerdo de paz ha supuesto un avance importante en materia de reconocimiento de los derechos de las mujeres en los territorios afectados, la práctica muestra que queda mucho camino por recorrer, debido a que la situación de las mujeres indígenas en las zonas extractivas continúa siendo extremadamente precaria y peligrosa. 
Una consolidación de la jurisdicción indígena en esos territorios, de todavía frágil gobernanza, podría ser una solución adecuada, que contribuyera a mejorar la situación de las mujeres indígenas en el ámbito del posacuerdo. Sin embargo, para lograr este objetivo dos son los requisitos que la jurisdicción especial indígena necesita asumir. Por un lado, resulta imperativo que incorpore y respete los estándares internacionales en materia de género y derechos humanos asumidos por Colombia. El segundo requisito consiste en garantizar que la mujer conforma un elemento activo, con capacidad de influencia y actuación, en el ámbito de la jurisdicción especial indígena; este extremo permitiría sentar las bases para revertir la concepción tradicional que se tenía respecto del rol de la mujer en el seno de las comunidades indígenas y contribuir a evitar actuaciones discriminatorias por razón de género.

Resulta pues patente la necesidad de que las autoridades y comunidades indígenas lleven a cabo ajustes internos en su organización y modo de actuar con el fin, no solo de clarificar la competencia jurisdiccional a aplicar en su territorio, sino para implementar los principios que en materia de representación, género y derechos humanos deben regir su organización, planteamientos y decisiones.

Así mismo, hemos podido ver cómo, de acuerdo con la jurisprudencia de la Corte Constitucional de Colombia, los usos y costumbres de una comunidad indigena deben primar sobre las normas legales dispositivas. Por lo tanto, y dado que las normas tradicionales deben ser susceptibles de adaptarse a la evolución de los tiempos, las autoridades indígenas estarían capacitadas, en principio, para regular nuevas circunstancias que se produjeran en sus territorios. Tras el análisis realizado, se considera que podría existir espacio suficiente dentro de la autonomía indígena para que las comunidades pudieran llevar a cabo una gestión propia de los recursos naturales sitos en sus territorios.

Sería de gran utilidad para este fin que la autonomía territorial de las comunidades indígenas se viera reforzada, en aras de garantizar la singularidad que el constituyente quiso otorgarles en su norma fundacional del año 1991. La Corte Constitucional de Colombia podría establecer un nuevo punto de partida jurisprudencial que permitiera revertir situaciones que alimentaron el conflicto colombiano. Este punto y aparte doctrinal 
permitiría reconocer la autonomía reforzada ${ }^{2}$ de las comunidades indígenas y la posibilidad de asumir las competencias en materia de gestión de la extracción de minerales.

Una interpretación innovadora en relación con la competencia de la jurisdicción indígena en la gestión de la extracción minera, respetando la soberanía nacional de los recursos naturales, favorecería el avance efectivo de la autonomía indígena reconocida en la carta magna colombiana. Esta iniciativa conllevaría necesariamente su adaptación a los estándares que, en materia de igualdad de género y respeto a los derechos humanos, deben servir de base para garantizar la paz, la estabilidad y el desarrollo a largo plazo

\section{Referencias}

Alianza Iniciativa de Mujeres Colombianas por la Paz (IMP), Asociación Colectivo Mujeres al Derecho, Casa de la Mujer, Católicas por el Derecho a Decidir Colombia; Centro de Estudios de Derecho, Justicia y Sociedad (Dejusticia); Centro de Investigación y Educación Popular Programa por la Paz... (2013). Una mirada a los derechos de las mujeres en Colombia", Informe alternativo presentado al Comité de la CEDAW - 2013. Bogotá: Enlace Publicitario Editores Ltda.

De Justicia, HRREC, DPLF, Fundar, Instituto de Defensa Legal. (2015). Amicus Curiae, "Estándares Comparados e Internacionales sobre el Derecho a la Consulta Previa, Libre e Informada", Caso Comunidades indígenas afectadas por la liberación al ambiente de soya genéticamente modificada- Amparos en Revisión: 241/2015, 270/2015 410/2015, 498/2015, 499/2015, 500/2015 y 198/2015. Recuperado de https://cdn.dejusticia.org/wp-content/uploads/2017/04/ fi_name_recurso_768.pdf

De Justicia, HRREC, DPLF. (2016). Amicus Curiae, "Estándares Comparados e Internacionales sobre el Derecho a la Consulta Previa, Libre e Informada" Caso San Miguel del Progreso- Amparo Indirecto 429/2016. Recuerado de https://www. academia.edu/33379219/Amicus_CSI_Mexico_San_Miguel_del_Progreso_Septiembre_2016

2 Autores como Samuel Baena sostienen la necesidad de una autonomía reforzada para las comunidades indígenas que les permita ir más allá de las competencias generales de las entidades territoriales. 
Anaya, J. (24 de abril de 2009). Principios internacionales aplicables a la consulta en relación con la reforma constitucional en materia de derechos de los pueblos indígenas en Chile, Relator Especial de Naciones Unidas sobre la situación de los derechos humanos y las libertades fundamentales de los indígenas.

Ariza, L. (2004). Identidad Indígena y Derecho Estatal en Colombia. Cuadernos Deusto de Derechos Humanos, (30).

Asamblea General. (16 de agosto de 2012). A/HRC/21/53, Estudio del Mecanismo de expertos sobre los derechos de los pueblos indígenas.

Asamblea General. (30 de julio de 2013). A/HRC/24/50, Estudio del Mecanismo de expertos sobre los derechos de los pueblos indígenas.

Asamblea General. (6 de agosto de 2015). A/HRC/30/41, Informe de la Relatora Especial sobre los derechos de los pueblos indígenas, Victoria Tauli Corpuz. Asamblea General. (10 de diciembre de 2007). A/RES/61/295, Declaración de las Naciones Unidas sobre los derechos de los pueblos indígenas.

Baena, S. (2015). La autonomía de las entidades territoriales indígenas. Revista Digital de Derecho Administrativo, (13), 99-133.

Barón Romero, D. (2013). Impactos de la minería en los derechos de las mujeres rurales en Colombia. Ginebra: Centro de Investigación y Educación Popular. CINEP, Ponencia presentada en la reunión sobre Mujeres Rurales del Comité CEDAW el 7 de octubre de 2013.

Bouvier, V. M. (4 de marzo de 2016). El género y el papel de las mujeres en el proceso de paz de Colombia ONU Mujeres. Recuperado de http://wps.unwomen.org/pdf/research/Bouvier_Women-in-Colombia-Peace-Process_ES.pdf

Bruno, C. (13 de agosto de 2017). Mujeres indígenas en las mil y una luchas. Colombiacheck, Colombia. Recuperado de https://colombiacheck.com/ investigaciones/mujeres-indigenas-en-las-mil-y-una-luchas.html

Comisión de Derechos Humanos de Los pueblos indígenas. (2018). Balance General de Vulneraciones a los DDHH e Infracciones al DIH contra los Pueblos Indigenas, Colombia 2017-2018, Segundo Informe.

Comisión Interamericana de Derechos Humanos. (18 de octubre de 2006). OEA/Ser.L/V/II. Doc. 67, CIDH.

Comisión Interamericana de Derechos Humanos. (30 diciembre de 2009). OEA/Ser.L/V/II., Doc. 56/09, Derechos de los pueblos indígenas y tribales sobre sus tierras ancestrales y recursos naturales: Normas y jurisprudencia del Sistema Interamericano de Derechos Humanos, CIDH.

Comisión Interamericana de Derechos Humanos. (28 de marzo de 2012). Audiencia sobre la situación de derechos humanos de las personas afectadas por las industrias extractivas en las Américas, $144^{\circ}$ Período de Sesiones, CIDH. 
Comisión Interamericana de Derechos Humanos. (14 de marzo de 2013). Audiencia sobre la situación de derechos humanos de los pueblos indígenas en Colombia, $147^{\circ}$ Período de Sesiones.

Comisión Interamericana de Derechos Humanos. (31 de diciembre de 2015). CIDH, OEA/Ser.L/V/II., Doc. 47/15,Pueblos Indígenas, Comunidades afrodescendientes, Industrias extractivas, $\mathrm{CIDH}$.

Comisión Interamericana de Derechos Humanos. (30 de julio de 2015). Encuentro regional sobre "Violaciones a los derechos humanos de los pueblos indígenas y afrodescendientes en el contexto de proyectos extractivos y turísticos".

Comisión Interamericana de Derechos Humanos. (3 de octubre de 2018). Denuncias de asesinatos, amenazas y desplazamiento forzado de personas defensoras de los derechos a los territorios afrodescendientes e indígenas en Colombia, CIDH, 169 Período de Sesiones.

Comité para la Eliminación de la Discriminación Racial. (1997). Recomendación general $\mathrm{N}^{\circ}$ XXIII relativa a los derechos de los pueblos indígenas, $51^{\circ}$ período de sesiones, CERD.

Comité para la Eliminación de la Discriminación Racial. (28 de agosto de 2015). CERD/C/COL/CO/15-16, Observaciones finales sobre el decimoquinto y decimosexto informes periódicos de Colombia.

Congreso de la República de Colombia. (6 de marzo de 1991). Ley 21 de 1991 por medio de la cual se aprueba el Convenio número 169 sobre pueblos indígenas y tribales en países independientes, adoptado por la 76a reunión de la Conferencia General de la OIT, Ginebra, 1989, Diario Oficial. № 39720.

Congreso de la República de Colombia. (9 de noviembre de 1994). Ley 165 de 1994 Por medio de la cual se aprueba el "Convenio sobre la Diversidad Biológica", hecho en Río de Janeiro el 5 de junio de 1992, Diario Oficial No. 41.589. Congreso de la República de Colombia. (15 de marzo de 1996). Ley 270, Estatutaria de la Administración de Justicia, Diario Oficial No. 42.745, modificada por las leyes 585 de 2000, 771 de 2002 y el Decreto 2637 de 2004.

Consejería Presidencial para los Derechos Humanos. (2015). Plan Nacional de Acción de Derechos Humanos y Empresas de Colombia 2015-2018, Gobierno de Colombia.

Consejo de Derechos Humanos. (15 de julio de 2009). A/HRC/12/34, Informe del Relator Especial sobre la situación de los derechos humanos y las libertades fundamentales de los indígenas, James Anaya.

Consejo de Derechos Humanos. (6 de julio de 2012). A/HRC/21/47, Informe del Relator Especial sobre la situación de los derechos humanos y las libertades fundamentales de los indígenas, James Anaya. 
Consejo de Derechos Humanos. (1 de julio de 2013). A/HRC/24/41, James Anaya, Informe del Relator Especial sobre los derechos de los pueblos indígenas, James Anaya.

Consejo de Derechos Humanos. (23 de marzo de 2017). A/HRC/34/3/Add.3, Informe anual del Alto Comisionado de las Naciones Unidas para los Derechos Humanos sobre la situación de los derechos humanos en Colombia.

Consejo de Derechos Humanos. (2 de marzo de 2018). A/HRC/37/3/Add.3, Informe anual del Alto Comisionado de las Naciones Unidas para los Derechos Humanos sobre la situación de los derechos humanos en Colombia.

Consejo de Seguridad de las Naciones Unidas. (31 de octubre de 2000). S/ RES/1325 (2000), Resolución, Naciones Unidas, 4213ª Sesión.

Consejo de Seguridad de las Naciones Unidas. (13 de octubre de 2015). S/ RES/2242 (2015), Resolución, Naciones Unidas, 7533ª Sesión.

Consejo Económico y Social. (16 de febrero de 2006). E/CN.4/2006/78, Informe del Relator Especial sobre la situación de los derechos humanos y las libertades fundamentales de los indígenas, Sr. Rodolfo Stavenhagen.

Consejo Económico y Social. (11 de febrero de 2011). E/C.19/2011/3, Situación de los pueblos indígenas en peligro de extinción en Colombia, Resumen del informe y recomendaciones de la misión del Foro Permanente a Colombia.

Consejo Superior de la Judicatura. (19 de julio de 2012). Sala Administrativa, No. SC 5780 - 1 No. GP 059 - 1, Acuerdo No. PSAA12-9614.

Consejo Superior de la Judicatura. (22 de enero de 2013). Sala Administrativa, Acuerdo No. PSAA13-9816.

Consejo Superior de la Judicatura. (2017). Propuesta de plan de acción 2017 Jurisdicción Especial Indígena, Colombia.

Corte Constitucional de la República de Colombia. (30 de mayo de 1994), Dr. Eduardo Cifuentes Muñoz, Sentencia No. T-254/94.

Corte Constitucional de la República de Colombia. (9 de abril 1996), Carlos Gaviria Díaz, Sentencia No. C-139/96.

Corte Constitucional de la República de Colombia. (8 de agosto de 1996). Carlos Gaviria Díaz, Sentencia T349/96.

Corte Constitucional de la República de Colombia. (18 de septiembre de 1998).

Eduardo Cifuentes Muñoz, Sentencia SU-510/98.

Corte Constitucional de la República de Colombia. (7 de junio de 2001). Marco Gerardo Monroy Cabra, Sentencia T-606/01.

Corte Constitucional de la República de Colombia. (14 de abril de 2008), Auto 092/08, Manuel José Cepeda Espinosa. 
Corte Constitucional de la República de Colombia. (26 de enero de 2009). Auto 004/09, Manuel José Cepeda Espinosa.

Corte Constitucional de la República de Colombia. (5 de agosto de 2010). Sentencia T-617/10, Dr. Luis Ernesto Vargas Silva.

Corte Constitucional de la República de Colombia. (10 de agosto de 2011). Sentencia T-601/11, Jorge Iván Palacio.

Corte Constitucional de la República de Colombia. (6 de julio de 2012). Sentencia T-514/12, Luis Ernesto Vargas Silva.

Corte Constitucional de la República de Colombia. (30 de octubre de 2012). Sentencia C-889 de 2012, Luis Ernesto Vargas Silva.

Corte Constitucional de la República de Colombia. (5 de marzo de 2014). Sentencia C-123/14, Alberto Rojas Ríos.

Corte Constitucional de la República de Colombia. (5 de agosto de 2016). Sentencia T-530/16, Dr. Luis Ernesto Vargas Silva.

Corte Constitucional de la República de Colombia. (12 de junio de 2017). Auto 266/17, Gloria Stella Ortiz Delgado.

Corte Constitucional de la República de Colombia. (26 de abril de 2017). Radicación No. 11001010200020160365700 (12420-31), Magistrada Doctora Julia Emma Garzón de Gómez, Conflicto positivo de jurisdicción / Ordinaria Penal - Indígena.

Corte Interamericana de Derechos Humanos. (28 noviembre 2007). Caso del Pueblo Saramaka v. Surinam, Reparaciones, Sentencia, Serie C. No 172.

Corte Interamericana de Derechos Humanos. (27 de junio de 2012). Caso Pueblo Indígena Kichwa de Sarayaku Vs. Ecuador. Fondo y reparaciones. Sentencia. Serie C No. 245.

Cruz Micán, D. B. (2017). Jurisdicción especial indígena en Colombia: un estudio comparado con la jurisdicción ordinaria (tesis de grado). Universidad Católica de Colombia. Bogotá, Colombia.

De la Cruz I, R. (2006). Regional Study in the Andean Countries: "Customary law in the protection of traditional knowledge". Recuperado de https://www.wipo. int/export/sites/www/tk/en/resources/pdf/study_cruz.pdf

Defensoría del Pueblo de Colombia. (2014). Jurisdicción Especial Indigena, Boletín $n^{\circ}$ 6, Bogotá.

Defensoría del Pueblo de Colombia. (2017). Informe Espacios Territoriales de Capacitación y Reincorporación para la paz, Bogotá.

Etchart, L. (2005). Progress in gender mainstreaming in Peace Support Operations. En Gender Mainstreaming in Conflict Transformation: Building Sustainable Peace, (pp. 56-81). Londres: The Commonwealth Secretariat. 
Human Rights Everywhere. (junio de 2011). Analysis of Mining in Indigenous Territories in Colombia, Desecrated land 2 Impact of Megaprojects on Indigenous Territories in Colombia MINING, HREV, Fact Sheet.

Instituto Kroc de Estudios Internacionales de Paz. (2017). Informe sobre el estado efectivo de implementación del acuerdo de paz en Colombia. Indiana: Universidad de Notre Dame.

Feo, J. (2019). La industria extractiva y los derechos humanos en el posconflicto colombiano. Revista Summa Iuris, 6(2), pp. 250-284.

Grupo de Naciones Unidas para el Desarrollo. (2009). Directrices sobre las cuestiones relativas a los pueblos indígenas. Nueva York: Naciones Unidas.

Jenkins, K. (2014). Women, Mining and Development: An Emerging Research Agenda. The Extractive Industries and Society, 1 (2)329-339.

León Linares, M. P., (2016). Balance de la autonomía indígena a la luz del Decreto 1953 de 2014 (tesis de grado). Pontificia Universidad Javeriana. Bogotá, Colombia.

Murua, F. (2018). Corte Interamericana de Derechos Humanos y derechos territoriales de los pueblos indígenas. Estudio de impacto de sentencias. Revista Anales de la Facultad de Ciencias Jurídicas y Sociales, (46), 260-272.

Organización de los Estados Americanos. (14 de junio de 2016). AG/RES. 2888 (XLVI-O/16), Declaración Americana sobre los derechos de los pueblos indígenas, Aprobada en la segunda sesión plenaria.

Organización de las Naciones Unidas. (10-14 de julio de 2017). Mecanismo de Expertos sobre los Derechos de los Pueblos Indígenas, Opinión 10: el ámbito empresarial y el acceso a servicios financieros para los pueblos indígenas, 10a sesión del MEDPI.

Organización Internacional del Trabajo. (1989). C169 - Convenio sobre pueblos indígenas y tribales, (núm. 169), Convenio sobre pueblos indígenas y tribales en países independientes (Entrada en vigor: 05 septiembre 1991), Adopción: Ginebra, $76^{a}$ reunión CIT (27 junio 1989.)

Organización Internacional del Trabajo - OIT (2013). Comprender el Convenio sobre pueblos indígenas y tribales. Manual para los mandantes tripartitos de la OIT.

Organización Nacional Indígena de Colombia. (2008). Verdades de los pueblos indígenas de Colombia que el gobierno desdibuja. ONIC, Rebelión [en línea]. Recuperado de http://www.rebelion.org/noticia.php?id=75421

Quintero Benavides A. (2013). Derechos en femenino, chacia un real camino a la igualdad? VI informe de derechos humanos de las mujeres de la Red Nacional de Mujeres 2010-2012. Bogotá. Corporación Sisma Mujer. 
República de Colombia, Constitución Política de Colombia. (4 de julio de 1991), Gaceta Constitucional número 114.

República de Colombia, Ley 1454 Orgánica de Ordenamiento Territorial (28 de junio de 2011). Diario Oficial 48115.

República de Colombia, Decreto Ley 1953 (7 de octubre 2014). Diario Oficial No. 49.297

República de Colombia, Decreto Ley 632 (11 de abril de 2018). Diario Oficial No. 50.561.

Sánchez Botero, E. (2009). La realización del pluralismo jurídico de tipo igualitario en Colombia. Nueva Antropología, 22(71) 31-49.

Sánchez Botero, E. (2005). Reflexiones en torno de la jurisdicción especial indígena en Colombia, Revista IIDH, 41, 226-250.

Santos Calderón, J. M. E Jiménez, T. (2016). Acuerdo Final para la Terminación del Conflicto y la Construcción de una Paz Estable y Duradera. Bogotá.

Simons, P. (2017). Unsustainable International Law: Transnational Resource Extraction and Violence against Women. 26, 415-434.

Tribunal Permanente de los Pueblos. (29 de mayo - 10 de junio del 2014). Sesión sobre la industria minera canadiense, Audiencia sobre América Latina, Veredicto, Montreal, Canadá. 